\title{
Efeito da Suplementação Enzimática em Rações com Farelo de Soja e Soja Integral Extrusada sobre a Digestibilidade de Nutrientes, o Fluxo de Nutrientes na Digesta Ileal e o Desempenho de Frangos ${ }^{1}$
}

\author{
Elis Regina de Moraes Garcia², Alice Eiko Murakami ${ }^{3}$, Antonio Ferriani Branco³, \\ Antonio Claudio Furlan ${ }^{3}$, Ivan Moreira ${ }^{3}$
}

\begin{abstract}
RESUMO - Três experimentos foram realizados com o objetivo de avaliar o efeito da suplementação enzimática em rações à base de milho e soja sobre o desempenho (Experimento 1), a digestibilidade de nutrientes (Experimento 2) e o desempenho e o fluxo de nutrientes na digesta ileal (Experimento 3) em frangos de corte. No Experimento 1, para o cálculo das rações experimentais, a composição química do farelo de soja (FS) e da soja integral extrusada (SIE) foi superestimada em $7 \%$ para os valores de EM e PB e 5\% para Met, Met+Cis e Lis (Trat. C, D e E) e 9\% para EM, 7\% para PB e 5\% para Met, Met+Cis e Lis (Trat. F, G e H), quando houve a adição de enzimas (Allzyme Vegpro ${ }^{\circledR}$ e Allzyme Lipase ${ }^{\circledR}$ ). Conclui-se que os valores de EM, PB e aminoácidos (Met, Met+Cis e Lis) da soja puderam ser superestimados em 9, 7 e 5\%, respectivamente, quando houve a adição de complexo multienzimático (Allzyme Vegpro ${ }^{\circledR}$ ) às rações para frangos de corte (1-42 dias), sem prejuízo ao desempenho das aves. Os tratamentos utilizados nos experimentos 2 e 3 foram: A e B - rações contendo farelo de soja (FS), sem e com adição de complexo multienzimático (Allzyme Vegpro ${ }^{\circledR}$ ); e C e D - rações contendo farelo de soja (FS) e soja integral extrusada (SIE), sem e com adição de complexo multienzimático (Allzyme Vegpro ${ }^{\circledR}$ ). No experimento 2, não foram observadas diferenças entre os tratamentos para os coeficientes de metabolização aparente de matéria seca, proteína bruta, energia bruta e a EMAn. No Experimento 3, para os períodos inicial (1-21 dias de idade), de crescimento (22-42 dias de idade) e total (1-42 dias de idade), não foram observadas diferenças no consumo de ração, no ganho de peso e na conversão alimentar das aves que receberam rações suplementadas com enzimas. Na determinação do fluxo de nutrientes na digesta ileal, não foram verificadas diferenças entre os tratamentos estudados, aos 21 e 42 dias de idade.
\end{abstract}

Palavras-chave: complexo multienzimático, farelo de soja, frango de corte, lipase, soja integral extrusada

\section{Enzymatic Supplementation on Soybean Meal and Full Fat Extruded Soybean Based Diet on the Digestibility of Nutrients, Ileal Digest Flow and Broiler Performance}

\begin{abstract}
Three trials were conducted to evaluate the effect of enzymatic supplementation of corn and soybean based diets on performance (Trial 1), nutrients digestibility (Trial 2), performance and nutrient flow in the ileal digesta (Trial 3 ) in broiler chickens. In Trial 1, for experimental diet formulation, the chemical composition of soybean meal (SM) and full fat extruded soybean (ES) were overestimated in 7\% for ME and CP, and 5\% for Met, Met+Cys and Lys (Treatment C, D, and $\mathrm{E}$ ) and $9 \%$ for ME, $7 \%$ for $\mathrm{CP}$ and $5 \%$ for Met, Met+Cys and Lys (Treatments F, G e H) when there was enzymes addition (Allzyme Vegpro ${ }^{\circledR}$ e Allzyme Lipase ${ }^{\circledR}$ ). It was concluded that ME, CP and amino acids (Met, Met+Cys and Lys) values can be overestimated in 9,7 and $5 \%$, respectively, when there was the addition of enzymatic complex to the broilers diets (142 days), without reducing bird performance. Treatments used on trials 2 and 3 were: A and B - diets based on soybean meal (SBM) with and without addition of multienzymatic complex (Allzyme Vegpro ${ }^{\circledR}$ ) and C and D - diets based on soybean meal $(\mathrm{SBM})$ and full fat extruded soybean (ES) with and without addition of multienzymatic complex (Allzyme Vegpro ${ }^{\circledR}$ ). In Trial 2 differences were not observed among treatments for coefficients of apparent metabolization of dry matter, crude protein, gross energy and $\mathrm{AME}_{\mathrm{n}}$. In trial 3, for initial period (1-21 days), growth period (22-42 days) and total period (1-42 days) differences were not observed in feed intake, weight gain and feed: gain among birds fed with diets supplemented with enzymes. In the determination of nutrient flow in ileal digesta, differences among studied treatments were not observed, for 21 and 42 days age.
\end{abstract}

Key Words: broiler, full fat extruded soybean, lipase, multienzymatic complex, soybean meal

\footnotetext{
1 Parte da Dissertação apresentada à UEM, pelo primeiro autor, como um dos requisitos para obtenção do título de Mestre em Zootecnia. ${ }^{2}$ Professor do Curso de Zootecnia - Universidade Estadual de Mato Grosso do Sul - Rodovia Aquidauana-Cera, Km 12 - $79200-000$ - Aquidauana - MS. E.mail:ermgarcia@hotmail.com

${ }^{3}$ Professor do Departamento de Zootecnia - UEM-CCA-DZO - Av. Colombo, 5790 - 87020-900 - Maringá - PR.
} 


\section{Introdução}

Com o crescente aumento na produção de frangos de corte nos últimos anos, os nutricionistas têm se empenhado em buscar soluções para atender às exigências nutricionais das aves, que, devido ao rápido crescimento e à conseqüente redução no tempo de abate, passaram a exigir alimentos de melhor qualidade.

É comum o uso de alimentos protéicos nas rações contendo grande quantidade de fatores antinutricionais e constituintes de baixa digestibilidade (CHARLTON, 1996). A soja, ao contrário do que se pensava, possui quantidade apreciável de polissacarídeos nãoamiláceos (PNA's) (WARD e FODGE, 1996) na forma de pectinas, hemiceluloses e oligassacarídeos (rafinose e estaquiose) (CHARLTON, 1996). Além desses PNA's, fatores antinutricionais como inibidores de proteases e lectinas estão amplamente distribuídos na soja e não podem ser degradados pelo sistema digestivo das aves (CLEÓPHAS et al., 1995).

Embora a indústria de rações utilize o tratamento térmico para eliminar esses fatores antinutricionais, SOTO-SALANOVA et al. (1996) relataram que níveis residuais de lectinas e atividades de inibidores de proteases se mostraram bastante razoáveis em diferentes amostras de farelo de soja.

Trabalhos recentes têm demonstrado respostas positivas quanto à digestibilidade de nutrientes e ao desempenho de aves alimentadas com rações à base de milho e soja, quando estas foram suplementadas com enzimas, como carboidrases, proteases, pectinases e alfa-galactosidase (McNab e Pugh, citados por CHARLTON, 1996; SCHANG, 1996; SEFTON e PERDOK, 1996; SOTO-SALANOVA et al., 1996; e GRAHAM, 1997).

LESLIE (1996) e LYONS (1996) afirmaram que o valor da digestibilidade de alguns nutrientes da soja pode ser superestimado em 7 a $9 \%$ para EM e de 5 a $7 \%$ para os aminoácidos, quando se utiliza a soja suplementada com enzimas como novo ingrediente nas rações.

O uso de lipase, em rações para aves, também tem sido uma nova alternativa com intuito de aumentar a digestão das gorduras principalmente em rações iniciais, visto que nesta fase o sistema enzimático do animal é imaturo; portanto, as aves são ineficientes na digestão total das gorduras (PUGH, 1993).

Em função disso, o objetivo deste trabalho foi avaliar o efeito da suplementação de enzimas em rações para frangos de corte, com farelo de soja e soja integral extrusada, por intermédio do desempenho e da determinação dos coeficientes de metabolização
1415

aparente da matéria seca (MS), proteína bruta (PB) e energia bruta (EB), a energia metabolizável aparente corrigida para nitrogênio (EMAn) e o fluxo de nutrientes na digesta ileal.

\section{Material e Métodos}

Foram realizados no Aviário da Fazenda Experimental de Iguatemi da Universidade Estadual de Maringá três experimentos, no período de maio a setembro de 1997.

\section{Experimento 1 - Desempenho}

Foram utilizados 1600 pintos de 1 dia de idade, machos, da linhagem Cobb. As aves foram alojadas em um galpão convencional dividido em boxes de $6,3 \mathrm{~m}^{2}$ com cobertura de telha francesa e lanternin, piso de concreto e paredes laterais de alvenaria com $0,30 \mathrm{~m}$ de altura e o restante com tela de arame até o telhado, providas de cortinas laterais. Foi colocada cama do tipo maravalha sobre o piso.

Na fase inicial, foram utilizados comedouros do tipo bandeja de 0,50 x 0,40 x 0,05 m e bebedouros do tipo copo de pressão até o quinto dia de idade, que foram, em seguida, substituídos gradativamente pelo comedouro tubular e bebedouro automático do tipo pendular.

Em cada box, foram utilizados um círculo de proteção e uma campânula como fonte de aquecimento para os pintos. No 7o dia de idade, as aves foram vacinadas, via ocular, contra as doenças Newcastle e Gumboro.

Foram fornecidas água e ração à vontade em um programa de alimentação dividido em duas fases, sendo a inicial do $1^{\underline{o}}$ ao $21^{\underline{o}}$ dia de idade, e a de crescimento, do $22^{\circ}$ ao $42^{\circ}$ dia de idade.

Os cálculos das rações foram feitos com base nas exigências da linhagem e na composição química dos alimentos, de acordo com ROSTAGNO et al. (1987) e CAFÉ (1993). As dietas experimentais foram isocalóricas, isoaminoacídicas para lisina e metionina + cistina, isocálcicas e isofosfóricas (Tabelas 1 e 2).

Os tratamentos utilizados foram:

A. Ração com farelo de soja (FS) sem complexo multienzimático (Controle);

B. Ração com farelo de soja + soja integral extrusada (SIE) sem complexo multienzimático;

C. Ração com farelo de soja com complexo multienzimático (+ 7\% EM e PB; 5\% AAs);

D. Ração com farelo de soja + soja integral extrusada com complexo multienzimático (+ $7 \%$ EM e PB; $5 \%$ AAs); 
1416 Rev. bras. zootec.

Tabela 1 - Composições percentual e calculada das dietas experimentais (Exp. 1)

Table 1 - Percentage and calculated compositions of the experimental diets (Exp. 1)

\begin{tabular}{|c|c|c|c|c|c|c|}
\hline \multirow[b]{2}{*}{$\begin{array}{l}\text { Ingredientes (\%) } \\
\text { Ingredients (\%) }\end{array}$} & \multicolumn{6}{|c|}{$\begin{array}{r}\text { Inicial } \\
\text { Initial }\end{array}$} \\
\hline & A & B & $\mathrm{C}$ & $\mathrm{D} / \mathrm{E}$ & $\mathrm{F}$ & $\mathrm{G} / \mathrm{H}$ \\
\hline $\begin{array}{l}\text { Milho } \\
\text { Corn }\end{array}$ & 54,43 & 54,61 & 59,42 & 59,84 & 59,77 & 58,65 \\
\hline Farelo de soja & 36,69 & 25,87 & 33,31 & 22,36 & 33,25 & 23,30 \\
\hline $\begin{array}{l}\text { Soybean meal } \\
\text { Soja extrusada }\end{array}$ & - & 13,00 & - & 13,00 & - & 13,00 \\
\hline $\begin{array}{l}\text { Full fat extruded soybean } \\
\text { Óleo de soja } \\
\text { Soybean oil }\end{array}$ & 4,21 & 1,91 & 2,52 & - & 2,23 & - \\
\hline $\begin{array}{l}\mathrm{L} \text {-lisina } \mathrm{HCl} \\
\text { L-lysine }\end{array}$ & 0,02 & 0,01 & 0,07 & 0,06 & 0,07 & 0,03 \\
\hline $\begin{array}{l}\text { DL metionina } \\
\text { DL-methionine }\end{array}$ & 0,21 & 0,22 & 0,21 & 0,23 & 0,21 & 0,22 \\
\hline $\begin{array}{l}\text { Fosfato bicálcico } \\
\text { Dicalcium phosphate }\end{array}$ & 1,81 & 1,80 & 1,82 & 1,81 & 1,82 & 1,81 \\
\hline $\begin{array}{l}\text { Calcário } \\
\text { Limestone }\end{array}$ & 1,12 & 1,07 & 1,14 & 1,09 & 1,14 & 1,08 \\
\hline $\begin{array}{l}\text { Sal comum } \\
\text { Salt }\end{array}$ & 0,40 & 0,40 & 0,40 & 0,40 & 0,40 & 0,40 \\
\hline $\begin{array}{l}\text { Suplem. } \min +\text { vit }^{1} \\
\text { Mineral-vitamin supl. }{ }^{1}\end{array}$ & 0,60 & 0,60 & 0,60 & 0,60 & 0,60 & 0,60 \\
\hline $\begin{array}{l}\text { Antioxidante }(\mathrm{BHT}) \\
\text { Antioxidant }(B H T)\end{array}$ & 0,01 & 0,01 & 0,01 & 0,01 & 0,01 & 0,01 \\
\hline $\begin{array}{l}\text { Complexo multienzimático } \\
\text { Multienzymatic complex }\end{array}$ & 0,10 & 0,10 & 0,10 & 0,10 & 0,10 & 0,10 \\
\hline $\begin{array}{l}\text { Lipase } \\
\text { Inerte } \\
\text { Inert } \\
\end{array}$ & $\begin{array}{l}0,10 \\
0,30\end{array}$ & $\begin{array}{l}0,10 \\
0,30\end{array}$ & $\begin{array}{l}0,10 \\
0,30\end{array}$ & $\begin{array}{l}0,10 \\
0,40\end{array}$ & $\begin{array}{l}0,10 \\
0,30\end{array}$ & $\begin{array}{l}0,10 \\
0,70\end{array}$ \\
\hline $\begin{array}{l}\text { Valores calculados } \\
\text { Calculated values }\end{array}$ & & & & & & \\
\hline $\begin{array}{l}\text { Proteína bruta }(\%) \\
\text { Crude protein }\end{array}$ & 21,50 & 21,50 & 21,50 & 21,50 & 21,50 & 21,80 \\
\hline $\begin{array}{l}\mathrm{EM}(\mathrm{kcal} / \mathrm{kg}) \\
M E\end{array}$ & 3078 & 3078 & 3078 & 3078 & 3078 & 3078 \\
\hline $\begin{array}{l}\text { Cálcio }(\%) \\
\text { Calcium }\end{array}$ & 0,99 & 0,99 & 0,99 & 0,99 & 0,99 & 0,99 \\
\hline $\begin{array}{l}\text { Fósforo disponível (\%) } \\
\text { Available phosphorus }\end{array}$ & 0,45 & 0,45 & 0,45 & 0,45 & 0,45 & 0,45 \\
\hline $\begin{array}{l}\text { Met + Cist (\%) } \\
\text { Methionine + Cystine }\end{array}$ & 0,89 & 0,89 & 0,89 & 0,89 & 0,89 & 0,89 \\
\hline $\begin{array}{l}\text { Lisina }(\%) \\
\text { Lysine }\end{array}$ & 1,19 & 1,19 & 1,19 & 1,19 & 1,19 & 1,19 \\
\hline
\end{tabular}

${ }^{1}$ Suplemento vitamínico e mineral (Mineral and vitaminic suplement. Composição por kg de produto (Composition perkg of product): Inicial (Initial): Vit. A, 2.000.000 UI; Vit. D, $20.000 \mathrm{UI}$; Vit. E, 4000 mg; Vit. K, 500 mg; Vit. B, 240 mg; Vit. B, 800 mg; Vit. B, $400 \mathrm{mg}$; Ác. fólico (Folic Ac.), $100 \mathrm{mg}$. Ác. nicotínico (Nicotinic ac.), $5000 \mathrm{mg}$; Biotina (Biotine), $16 \mathrm{mg}$; Ác. pantotênico (Pantothenic Ac.), 2100 mg; Colina (Choline), 60.000 mg; Vit. B 12,2000 mg; Fe, 10.000 mg; Cu, 1600 mg; Mn, 12.000 mg; Co, 80 mg; Zn, 10.000 mg; I, 120 mg; Se, 40 mg; Antioxidante (Antioxidant), 20.000 mg; Metionina (Methionine), 217.800 mg; Coccidiostático (Coccidiostatic), 20.000 mg; Veículo q.s.p. (Vehicle q.s.p), $1000 \mathrm{~g}$.

E. Ração com farelo de soja + soja integral extrusada com complexo multienzimático + lipase (+ 7\% EM e PB; $5 \%$ AAs);

F. Ração com farelo de soja com complexo multienzimático (+ 9\% EM e 7\%PB; 5\% AAs);

G. Ração com farelo de soja + soja integral extrusada com complexo multienzimático (+ 9\% EM e $7 \% \mathrm{~PB} ; 5 \% \mathrm{AAs})$; e

H. Ração com farelo de soja + soja integral extrusada com complexo multienzimático + lipase (+ $9 \%$ EM e $7 \%$ PB; $5 \%$ AAs).

Para o cálculo das rações experimentais, as com- 
GARCIA et al.

Tabela 2 - Composições percentual e calculada das dietas experimentais (Exp. 1)

Table 2 - Percentage and calculated compositions of the experimental diets (Exp.1)

\begin{tabular}{|c|c|c|c|c|c|c|}
\hline \multirow[b]{2}{*}{$\begin{array}{l}\text { Ingredientes (\%) } \\
\text { Ingredients (\%) }\end{array}$} & \multicolumn{6}{|c|}{$\begin{array}{l}\text { Crescimento } \\
\text { Growth }\end{array}$} \\
\hline & A & B & $\mathrm{C}$ & $\mathrm{D} / \mathrm{E}$ & F & $\mathrm{G} / \mathrm{H}$ \\
\hline $\begin{array}{l}\text { Milho } \\
\text { Corn }\end{array}$ & 60,70 & 60,81 & 64,88 & 65,90 & 65,20 & 64,88 \\
\hline $\begin{array}{l}\text { Farelo de soja } \\
\text { Soybean meal }\end{array}$ & 30,76 & 18,37 & 27,93 & 15,25 & 27,87 & 16,00 \\
\hline $\begin{array}{l}\text { Soja extrusada } \\
\text { Full fat extruded soybean }\end{array}$ & - & 15,00 & - & 15,00 & - & 15,00 \\
\hline $\begin{array}{l}\text { Óleo de soja } \\
\text { Soybean oil }\end{array}$ & 4,50 & 1,86 & 3,08 & - & 2,83 & - \\
\hline $\begin{array}{l}\text { L-lisina } \mathrm{HCl} \\
\text { L-lysine }\end{array}$ & 0,01 & - & 0,05 & 0,05 & 0,05 & 0,04 \\
\hline $\begin{array}{l}\text { DL metionina } \\
\text { DL-methionine }\end{array}$ & 0,17 & 0,18 & 0,17 & 0,19 & 0,17 & 0,18 \\
\hline $\begin{array}{l}\text { Fosfato bicálcico } \\
\text { Dicalcium phosphate }\end{array}$ & 1,57 & 1,56 & 1,58 & 1,56 & 1,57 & 1,56 \\
\hline $\begin{array}{l}\text { Calcário } \\
\text { Limestone }\end{array}$ & 0,93 & 0,86 & 0,95 & 0,89 & 0,95 & 0,88 \\
\hline $\begin{array}{l}\text { Sal comum } \\
\text { Salt }\end{array}$ & 0,35 & 0,35 & 0,35 & 0,35 & 0,35 & 0,35 \\
\hline $\begin{array}{l}\text { Suplem. min }+ \text { vit }^{1} \\
\text { Mineral-vitamin supl. }\end{array}$ & 0,50 & 0,50 & 0,50 & 0,50 & 0,50 & 0,50 \\
\hline $\begin{array}{l}\text { Antioxidante (BHT) } \\
\text { Antioxidant }(B H T)\end{array}$ & 0,01 & 0,01 & 0,01 & 0,01 & 0,01 & 0,01 \\
\hline $\begin{array}{l}\text { Complexo multienzimático } \\
\text { Multienzymatic complex }\end{array}$ & 0,10 & 0,10 & 0,10 & 0,10 & 0,10 & 0,10 \\
\hline Lipase & 0,10 & 0,10 & 0,10 & 0,10 & 0,10 & 0,10 \\
\hline Inerte & 0,30 & 0,30 & 0,30 & 0,10 & 0,30 & 0,40 \\
\hline
\end{tabular}

Valores calculados

Calculated values

\begin{tabular}{|c|c|c|c|c|c|c|}
\hline Proteína bruta (\%) & 19,30 & 19,30 & 19,30 & 19,30 & 19,30 & 19,50 \\
\hline $\begin{array}{l}\text { Crude protein } \\
\mathrm{EM}(\mathrm{kcal} / \mathrm{kg})\end{array}$ & 3180 & 3180 & 3180 & 3180 & 3180 & 3180 \\
\hline$M E(\mathrm{kcal} / \mathrm{kg})$ & & & & & & \\
\hline $\begin{array}{l}\text { Cálcio }(\%) \\
\text { Calcium }\end{array}$ & 0,84 & 0,84 & 0,84 & 0,84 & 0,84 & 0,84 \\
\hline Fosforo disponível (\%) & 0,40 & 0,40 & 0,40 & 0,40 & 0,40 & 0,40 \\
\hline $\begin{array}{l}\text { Met + Cist }(\%) \\
\text { Methionine+ Cystine }\end{array}$ & 0,79 & 0,79 & 0,79 & 0,79 & 0,79 & 0,79 \\
\hline Lisina (\%) & 1,03 & 1,03 & 1,03 & 1,03 & 1,03 & 1,03 \\
\hline
\end{tabular}

Suplemento vitamínico e mineral (Mineral and Vitaminic suplement). Composição por kg de produto (Composition perkg ofproduct):

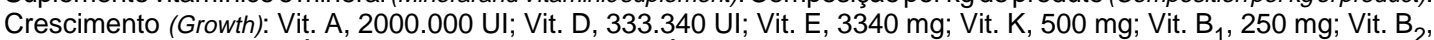
84 mg; Vit. B , 417 mg; Ác. fólico (Folic. Ac.), 100 mg; Ác. nicotínico (Nicotinic. Ac.), 3000 mg; Biotina (Biotine), 13,5 mg; Ác. pantotênico (Pantothenic Ac.), 2170 mg; Colina (Choline), 50.000 mg; Vit. B 12 , 2084 mg; Fe, 9170 mg; Cu, 1340 mg; $\mathrm{Mn}, 10.940 \mathrm{mg}$; Co, $83 \mathrm{mg} ; \mathrm{Zn}, 9170 \mathrm{mg} ; \mathrm{I}, 134 \mathrm{mg} ;$ Se, $37 \mathrm{mg}$; Antioxidante (Antioxidant), 16.670 mg; Metionina (Methionine), 255.840 mg; Coccidiostático (Coccidiostatic), 10.000 mg; Veículo q.s.p., $1000 \mathrm{~g}$.

posições químicas do farelo de soja e da soja integral extrusada foram superestimadas em $7 \%$ para os valores de EM e PB e 5\% para metionina, metionina + cistina e lisina, para os tratamentos C, D e E; em 9\% para os valores de EM, 7\% para $\mathrm{PB}$; e $5 \%$ para metionina, metionina + cistina e lisina, para os tratamentos $\mathrm{F}, \mathrm{G}$ e $\mathrm{H}$.
O complexo multienzimático (Allzyme Vegpro ${ }^{\circledR}$ ) contendo alfa-galactosidase, pectinases, celulase, proteases e a enzima Lipase (Allzyme Lipase ${ }^{\circledR}$ ) foram fornecidos pela empresa Alltech do Brasil Agroindustrial Ltda. e misturados à ração na proporção de $1,0 \mathrm{~kg}$ por tonelada de ração, de acordo com as recomendações do fabricante. 
1418 Rev. bras. zootec.

As variáveis estudadas foram ganho de peso, consumo de ração e conversão alimentar. As rações foram pesadas semanalmente e os animais, a cada troca de rações.

O delineamento experimental foi inteiramente casualizado, com oito tratamentos, quatro repetições e 50 aves por unidade experimental. As variáveis de desempenho foram submetidas à análise de variância e para a comparação das médias, utilizou-se o teste Tukey $(\mathrm{P}<0,05)$.

\section{Experimento 2 - Digestibilidade}

Neste experimento, foi utilizada a metodologia tradicional de coleta total de excretas em frangos de corte de 15 a 24 dias de idade, sendo cinco dias para adaptação às dietas experimentais e cinco dias para coletas das excretas.

Foram utilizados 64 pintos de corte, machos, da linhagem Cobb, distribuídos em um delineamento inteiramente casualizado com quatro tratamentos, quatro repetições e quatro aves por unidade experimental.

Os pintos foram alojados em 16 gaiolas de arame galvanizado, sendo cada gaiola destinada a uma repetição. Durante todo o período experimental, foram fornecidas água e ração à vontade, sendo que, para evitar o desperdício, o fornecimento de ração foi feito várias vezes ao dia.

Os tratamentos utilizados foram:

A. Ração com farelo de soja sem complexo multienzimático (FS s/ CM);

B. Ração com farelo de soja com complexo multienzimático (FS c/ CM);

C. Ração com farelo de soja + soja integral extrusada sem complexo multienzimático (FS+SIE s/CM); e

D. Ração com farelo de soja + soja integral extrusada com complexo multienzimático (FS+SIE c/ CM).

Os cálculos das rações foram feitos com base nas exigências da linhagem e na composição química dos alimentos, de acordo com ROSTAGNO et al. (1987) e CAFÉ (1993). As dietas experimentais foram isocalóricas, isoaminoacídicas para lisina e metionina + cistina, isocálcicas e isofosfóricas (Tabela 3), sendo utilizadas neste experimento aquelas destinadas ao período inicial.

O complexo multienzimático (Allzyme Vegpro ${ }^{\circledR}$ ) contendo alfa-galactosidase, pectinases, celulase e proteases foi fornecido pela empresa Alltech Agroindustrial do Brasil Ltda. e misturado à ração na proporção de $1,0 \mathrm{~kg}$ por tonelada de ração, de acordo com as recomendações do fabricante.

Após o período de adaptação, iniciou-se a coleta das excretas, utilizando o óxido férrico (2\%) na ração como marcador do início e final da coleta. Para a coleta das excretas, foram utilizadas bandejas da própria gaiola, que foram forradas com plástico para evitar perda de material. O intervalo das coletas foi de 12 horas, durante todo o período experimental.

As excretas foram acondicionadas em sacos plásticos, devidamente identificados por repetição e armazenados a $5^{\circ} \mathrm{C}$ após cada coleta. No final do período experimental, determinou-se, por repetição, a quantidade de ração consumida, bem como a quantidade total de excretas.

Para determinação da amostra seca ao ar (ASA) das excretas, as mesmas foram descongeladas, reunidas por repetição, homogeneizadas, pesadas e colocadas em estufa de ventilação forçada, à temperatura de $55^{\circ} \mathrm{C}$ por 72 horas.

Após a pré-secagem, as excretas foram moídas e acondicionadas para análises posteriores. Foram utilizadas amostras das rações e das excretas, de acordo com cada repetição, para a realização das análises químicas de matéria seca, energia bruta e proteína bruta, de acordo com as metodologias descritas por SILVA (1990).

Combase nos dados laboratoriais, foram calculados os valores dos coeficientes de metabolização aparente da matéria seca (CMAMS), energia bruta (CMAEB) e proteína bruta (CMAPB) e a energia metabolizável aparente corrigida para nitrogênio (EMAn) das rações experimentais.

As variáveis de digestibilidade foram submetidas à análise de variância e, para a comparação das médias, utilizou-se o teste Tukey $(\mathrm{P}<0,05)$.

Experimento 3 - Desempenho e fluxo de nutrientes na digesta ileal

Foram utilizados 320 pintos de 1 dia de idade, machos, da linhagem Cobb. As aves foram alojadas em um galpão convencional, dividido em boxes de $6,3 \mathrm{~m}^{2}$ com cobertura de telha francesa e lanternin, piso de concreto e paredes laterais de alvenaria com $0,30 \mathrm{~m}$ de altura e o restante com telha de arame até o telhado, providas de cortinas laterais. Foi colocada cama do tipo maravalha sobre o piso.

$\mathrm{Na}$ fase inicial, foram utilizados comedouros do tipo bandeja de 0,50 x 0,40 x 0,05 m e bebedouros do tipo copo de pressão até o quinto dia de idade, que foram substituídos gradativamente pelo comedouro tubular e bebedouro automático do tipo pendular.

Em cada box, foram utilizados um círculo de proteção e uma campânula como fonte de aqueci- 
GARCIA et al.

Tabela 3 - Desempenho de frangos de corte alimentados com rações contendo farelo de soja (FS) e soja integral extrusada (SIE), suplementadas ou não com complexo multienzimático (CM) e lipase

Table 3 - Performance of broilers fed diets with soybean meal (SM) and full fat extruded soybean (ES) supplemented or not multienzymatic complex (MC) and lipase

\begin{tabular}{|c|c|c|c|}
\hline $\begin{array}{l}\text { Tratamentos } \\
\text { Treatments }\end{array}$ & $\begin{array}{c}\text { Consumo de ração }(\mathrm{g})^{1} \\
\text { Feed intake }(\mathrm{g})^{l}\end{array}$ & $\begin{array}{l}\text { Ganho de peso }(\mathrm{g})^{1} \\
\text { Weight gain }(g)^{1}\end{array}$ & $\begin{array}{c}\text { Conversão alimentar }{ }^{1} \\
\text { Feed: }^{2} \text { ain ratio }\end{array}$ \\
\hline & & 1 a 21 dias & \\
\hline A - FS & $1101,27^{\mathrm{ab}}$ & $780,49^{\mathrm{a}}$ & $1,375^{\mathrm{a}}$ \\
\hline $\begin{array}{l}A-S M \\
\mathrm{~B}-\mathrm{FS}+\mathrm{SIE}\end{array}$ & $1043,70^{\mathrm{b}}$ & $729,19^{\mathrm{b}}$ & $1,422^{b}$ \\
\hline $\begin{array}{l}B-S M+E S \\
C-F S+C M \\
C-S M+M C\end{array}$ & $1076,20^{\mathrm{ab}}$ & $756,31^{\mathrm{ab}}$ & $1,435^{\mathrm{b}}$ \\
\hline $\begin{array}{l}C-S M+M C \\
\mathrm{D}-\mathrm{FS}+\mathrm{SIE}+\mathrm{CM} \\
D-S M+E S+M C\end{array}$ & $1075,05^{\mathrm{ab}}$ & $729,93^{\mathrm{b}}$ & $1,433^{\mathrm{b}}$ \\
\hline $\begin{array}{l}D-S M+E S+M C \\
\mathrm{E}-\mathrm{FS}+\mathrm{SIE}+\mathrm{CM}+\text { lipase } \\
E-S M+E S+M C+\text { lipase }\end{array}$ & $1077,90^{\mathrm{ab}}$ & $734,58^{\mathrm{b}}$ & $1,433^{b}$ \\
\hline $\begin{array}{l}\mathrm{F}-\mathrm{FS}+\mathrm{CM} \\
F-S M+M C\end{array}$ & $1117,85^{\mathrm{a}}$ & $757,39^{\mathrm{ab}}$ & $1,434^{\mathrm{b}}$ \\
\hline $\begin{array}{l}\mathrm{G}-\mathrm{FS}+\mathrm{SIE}+\mathrm{CM} \\
G-S M+E S+M C+\text { lipase }\end{array}$ & $1113,75^{\mathrm{a}}$ & $750,78^{\mathrm{ab}}$ & $1,425^{\mathrm{b}}$ \\
\hline $\begin{array}{l}\mathrm{H}-\mathrm{FS}+\mathrm{SIE}+\mathrm{CM}+\text { lipase } \\
H-S M+E S+M C+\text { lipase }\end{array}$ & $1087,00^{\mathrm{ab}}$ & $731,75^{\mathrm{b}}$ & $1,429^{b}$ \\
\hline $\mathrm{CV}(\%)$ & 2,80 & 2,88 & 1,32 \\
\hline & & 22 a 42 dias & \\
\hline $\begin{array}{l}\text { A - FS } \\
A-S M\end{array}$ & 3281,50 & 1735,37 & 2,059 \\
\hline B-FS+SIE & 3225,00 & 1694,25 & 1,986 \\
\hline $\begin{array}{l}\mathrm{C}-\mathrm{FS}+\mathrm{CM} \\
C-S M+M C\end{array}$ & 3239,75 & 1714,34 & 2,018 \\
\hline $\begin{array}{l}\mathrm{D}-\mathrm{FS}+\mathrm{SIE}+\mathrm{CM} \\
D-S M+E S+M C\end{array}$ & 3132,75 & 1691,97 & 2,067 \\
\hline $\begin{array}{l}\text { E- FS+SIE + CM + lipase } \\
E-S M+E S+M C+\text { lipase }\end{array}$ & 3285,50 & 1676,97 & 1,989 \\
\hline $\begin{array}{l}\mathrm{F}-\mathrm{FS}+\mathrm{CM} \\
F-S M+M C\end{array}$ & 3335,50 & 1701,14 & 2,080 \\
\hline $\begin{array}{l}\mathrm{G}-\mathrm{FS}+\mathrm{SIE}+\mathrm{CM} \\
G-S M+E S+M C+\text { linase }\end{array}$ & 3266,00 & 1689,42 & 2,007 \\
\hline $\begin{array}{l}\mathrm{H}-\mathrm{FS}+\mathrm{SIE}+\mathrm{CM}+\text { lipase } \\
H-S M+E S+M C+\text { lipase } \\
\end{array}$ & 3307,25 & 1741,57 & 2,019 \\
\hline $\mathrm{CV}(\%)$ & 4,64 & 3,78 & 4,25 \\
\hline & & 1 a 42 dias & \\
\hline $\begin{array}{l}\text { A - FS } \\
A-S M\end{array}$ & 4383,09 & 2515,84 & 1,825 \\
\hline $\begin{array}{l}\mathrm{B}-\mathrm{FS}+\mathrm{SIE} \\
B-S M+E S\end{array}$ & 4268,73 & 2423,45 & 1,791 \\
\hline $\begin{array}{l}\mathrm{C}-\mathrm{FS}+\mathrm{CM} \\
C-S M+E S+M C\end{array}$ & 4318,83 & 2470,65 & 1,814 \\
\hline $\begin{array}{l}\mathrm{D}-\mathrm{FS}+\mathrm{SIE}+\mathrm{CM} \\
D-S M+E S+M C\end{array}$ & 4207,73 & 2421,89 & 1,846 \\
\hline $\begin{array}{l}\mathrm{E}-\mathrm{FS}+\mathrm{SIE}+\mathrm{CM}+\text { lipase } \\
E-S M+E S+M C+\text { lipase }\end{array}$ & 4363,55 & 2411,55 & 1,806 \\
\hline $\begin{array}{l}\mathrm{F}-\mathrm{FS}+\mathrm{CM} \\
F-S M+M C\end{array}$ & 4453,55 & 2458,53 & 1,859 \\
\hline $\begin{array}{l}\mathrm{G}-\mathrm{FS}+\mathrm{SIE}+\mathrm{CM} \\
G-S M+E S+M C+\text { lipase }\end{array}$ & 4379,65 & 2440,20 & 1,803 \\
\hline $\begin{array}{l}\mathrm{H}-\mathrm{FS}+\mathrm{SIE}+\mathrm{CM}+\text { lipase } \\
H-S M+E S+M C+\text { lipase }\end{array}$ & 4394,38 & 2473,30 & 1,828 \\
\hline CV $(\%)$ & 3,71 & 2,74 & 3,04 \\
\hline
\end{tabular}

${ }^{1}$ Médias, na coluna, seguidas de letras iguais, não diferem pelo teste Tukey $(P>0,05)$.

${ }^{1}$ Means, within a column, followed by the same letters do not differ by Tukey test $(P>.05)$. 
1420 Rev. bras. zootec.

mento para os pintos. No sétimo dia de idade, as aves foram vacinadas via ocular contra as doenças Newcastle e Gumboro.

Foram fornecidas água e ração à vontade em um programa de alimentação dividido em duas fases, sendo a inicial do $1^{\circ}$ ao $21^{\circ}$ dia de idade, e a de crescimento, do $22^{\circ}$ ao $42^{\circ}$ dias de idade.

Os tratamentos foram os mesmos utilizados no experimento de digestibilidade (experimento 2) e as dietas experimentais estão apresentadas na Tabela 3 (períodos inicial e de crescimento).

O complexo multienzimático (Allzyme Vegpro ${ }^{\circledR}$ ) contendo alfa-galactosidase, pectinases, celulase e proteases foi fornecido pela empresa Alltech do Brasil Agroindustrial Ltda. e misturado à ração na proporção de $1,0 \mathrm{~kg}$ por tonelada de ração, de acordo com as recomendações do fabricante.

As variáveis estudadas foram ganho de peso, consumo de ração, conversão alimentar e fluxo de nutrientes na digesta ileal. As rações foram pesadas semanalmente, assim como os animais, a cada troca de rações, objetivando o cálculo do ganho de peso, do consumo de ração e da conversão alimentar.

Para a determinação do fluxo de nutrientes na digesta ileal aos 21 e 42 dias de idade, foram utilizadas duas aves por repetição, respectivamente.

Utilizou-se óxido crômico - $\mathrm{Cr}_{2} \mathrm{O}_{3}(2 \%$-p/p) como marcador externo para determinação do fluxo de digesta (MS) no trato digestório.

No dia anterior à coleta de material (21 e 42 dias de idade), pesou-se a quantidade de ração estimada para o consumo médio das aves e misturou-se óxido crômico. As análises de cromo da ração e da digesta ileal foram efetuadas de acordo com WILLIAMS et al. (1962).

Após a retirada de cada ave dos boxes, a ração foi pesada para determinação do consumo médio, no período de 24 horas.

As aves foram abatidas por deslocamento cervical, sendo efetuada a coleta da digesta ileal logo após o abate. O íleo foi delimitado entre o divertículo de Meckel's e a junção íleo-ceco-cólica. O conteúdo ileal foi coletado, pesado e seco em estufa $\left(55^{\circ} \mathrm{C}\right)$ por 72 horas. Depois de seco, o material foi moído em moinho de bola para que fossem efetuadas análises posteriores.

Para a realização das análises, as amostras de digesta ileal foram preparadas segundo KREIKEMEIER e HARMON (1995). Nas amostras de digesta ileal, coletadas aos 21 e 42 dias de idade, foram efetuadas análises de alfa-glicosídeos solúveis e insolúveis em etanol, de acordo com a metodologia proposta por POORE et al. (1989), adaptada por PEREIRA e ROSSI (1995) para determinação da glicose, por intermédio do kitenzimático-ENZCOLOR.

$\mathrm{O}$ delineamento experimental foi inteiramente casualizado com quatro tratamentos, quatro repetições e 20 aves por unidade experimental. As análises das variáveis de desempenho e do fluxo de nutrientes na digesta ileal foram submetidas à análise de variância e para a comparação das médias, utilizou-se o teste Tukey $(\mathrm{P}<0,05)$.

\section{Resultados e Discussão}

\section{Experimento 1 - Desempenho}

Os resultados de desempenho das aves estão apresentados na Tabela 4.

Para o período inicial (1-21 dias) não foram observadas diferenças no consumo de ração entre as aves que receberam como fonte protéica apenas o farelo de soja, com a adição ou não de complexo enzimático. Este resultado confirma o efeito das enzimas sobre a metabolização dos nutrientes da soja, conforme relatado por LESLIE (1996) e LYONS (1996).

As aves que receberam farelo de soja (FS) + soja integral extrusada (SIE) suplementada com complexo multienzimático apresentaram maior consumo de ração, quando se superestimou o valor de EM da soja em $9 \%$, comparadas àquelas que não receberam a adição de enzimas nas rações.

Por outro lado, quando se utilizou FS+SIE suplementada com complexo multienzimático e lipase, não foi observada esta diferença no consumo de ração, o que provavelmente pode ter ocorrido devido à atuação da lipase, melhorando a digestibilidade das lipídeos e aumentando, por conseguinte a energia disponível da ração, uma vez que, nas aves jovens, a atividade da lipase pancreática é fator limitante na digestão de lipídios (KROGDAHL e SELL, 1989; PUGH, 1993).

O ganho de peso foi semelhante entre as aves alimentadas com FS, com ou sem a suplementação de enzimas. Entretanto, as aves que receberam a ração controle apresentaram melhor conversão alimentar. Trabalhos realizados por CHARLTON (1996) e SEFTON e PERDOK (1996) demonstraram que a adição de enzimas em dietas inicias para frangos, à base de milho e soja (sem redução nos níveis de nutrientes), embora tenha aumentado o ganho de peso, não promoveu melhorias na conversão alimentar.

Ao comparar os tratamentos contendo FS+SIE 
GARCIA et al.

Tabela 4 - Composição percentual e calculada das dietas experimentais (Exp. 2 e 3)

Table 4 - Percentage and calculated compositions of experimental diets (Exp. 2 and 3)

\begin{tabular}{lccccc}
\hline & \multicolumn{3}{c}{$\begin{array}{c}\text { Inicial } \\
\text { Initial }\end{array}$} & & \multicolumn{2}{c}{ Crescimento } \\
Growth
\end{tabular}

Valores calculados

Calculated values

\begin{tabular}{|c|c|c|c|c|}
\hline Proteína bruta (\%) & 21,62 & 21,61 & 19,37 & 19,36 \\
\hline $\begin{array}{l}\text { Crude protein } \\
\mathrm{EM}(\mathrm{kcal} / \mathrm{kg})\end{array}$ & 2950 & 2950 & 3050 & 3050 \\
\hline $\begin{array}{l}M E \\
\text { Cálcio (\%) } \\
\text { Calcium }\end{array}$ & 0,99 & 0,99 & 0,84 & 0,84 \\
\hline $\begin{array}{l}\text { Fósforo disponível (\%) } \\
\text { Available phosphorus }\end{array}$ & 0,45 & 0,45 & 0,40 & 0,40 \\
\hline $\begin{array}{l}\text { Met + Cist (\%) } \\
\text { Methionine + Cystine }\end{array}$ & 0,89 & 0,89 & 0,79 & 0,79 \\
\hline $\begin{array}{l}\text { Lisina }(\%) \\
\text { Lysine }\end{array}$ & 1,19 & 1,19 & 1,03 & 1,03 \\
\hline
\end{tabular}

1 NUTREMIX-Suplemento vitamínico e mineral (Mineral and Vitaminic supplement). Composição por kg de produto: Inicial: Vit. A-2.000.000 UI; Vit. D-320.000 Ul; Vit. E-4000 mg; Vit. K-500 mg; Vit. B B $_{1}-240$ mg; Vit. $B_{2}-800$ mg; Vit. B -400 mg; Ác. Fólico-100 mg; Ác. Nicotínico-5000 mg; Biotina-16 mg; Ác. Pantotênico-2100 mg; Colina-60.000 mg; Vit. B $12-2.000$ mg; Fe- 10.000 mg; Cu-1600 mg; Mn-12.000 mg; Co-80 mg; Zn-10.000 mg; I-120 mg; Se-40 mg; Antioxidante-20.000 mg; Metionina- 217.800 mg; Coccidiostático-20.000 mg; Veículo q.s.p.-1000 g. Crescimento: Vit. A-2.000.000 UI; Vit. D-333.340 UI; Vit. E-3.340 mg; Vit. K-500 mg; Vit. $B_{1}-250 \mathrm{mg}$; Vit. $B_{2}-84 \mathrm{mg}$; Vit. $\mathrm{B}_{6}-417 \mathrm{mg}$; Ác. Fólico-100 mg; Ác. Nicotínico-3000 mg; Biotina-13,5 mg; Ác. Pantotênico-2170 mg; Colina-50.000 mg; Vit. B $12-2.084$ mg; Fe-9170 mg; Cu-1340 mg;Mn-10.940 mg; Co-83 mg; Zn-9170 mg; I-134 mg; Se-37 mg; Antioxidante-16.670 mg; Metionina- 255.840 mg; Coccidiostático-10.000 mg; Veículo q.s.p.-1000 g

1 NUTREMIX-.Mineral and Vitaminic supplement. Composition per kg by product:Initial: Vit. A-2.000.000 Ul; Vit. D-333.340 Ul: Vit. E-3340 mg: Vit. K-500 mg: Vit. B, $-250 \mathrm{mg}$ : Vit. B2-84 mg: Vit. B B $_{6} 417 \mathrm{mg}$; Folic Ac. $-100 \mathrm{mg}$ : Nicotinic Ac. - 3000 mg;Biotine-13,5 mg; Pantothenic Ac. $2170 \mathrm{mg}$;Choline-50.000 mg; Vit. B 1 - $^{-2084 ~ m g ; F e-9170 ~ m g ; C u-1340 ~ m g ; ~ M n-10.940 ~}$ mg:Co-83 mg:Zn-9170 mg: I-134 mg: Se-37 mg:Antioxidant-16.670 mg:Methionine-255.840 mg:Coccidiostatic-10.000 mg; Vehicle q.s.p.-1000 g. Growth: Vit. A-2.000.000 Ul; Vit. D-333.340 Ul; Vit. E-3340 mg; Vit. K-500 mg; Vit. B1-250 mg; Vit. B- ${ }_{2}-84 \mathrm{mg}$;Vit. $B_{6}-417 \mathrm{mg}$; Folic. Ac.-100 mg; Nicotinic. Ac.-3000 mg;Biotine-13,5 mg; Pantothenic Ac-2170 mg; Choline-

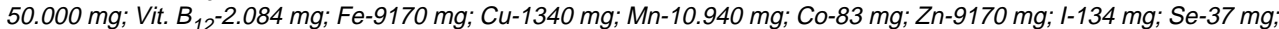
Antioxidant-16.670 mg; Methionine- $255.840 \mathrm{mg}$; Coccidiostatic-10.000 mg; Vehicle - $1000 \mathrm{~g}$. 
1422 Rev. bras. zootec.

com ou sem adição de enzimas, não foram verificadas diferenças entre as aves, para o ganho de peso e para a conversão alimentar. Estes resultados sugerem que a inclusão da SIE, em função do processamento, pode ter facilitado a atuação das enzimas, visto que a extrusão promove aumento na disponibilidade dos nutrientes, facilitando a hidrólise enzimática, conforme relatado por MARSMAN et al. (1995).

No período de crescimento (22-42 dias) e no período total (1-42 dias), não foram observadas diferenças entre os tratamentos em nenhuma das variáveis estudadas, evidenciando o efeito das enzimas nestes períodos, estando de acordo com SOTOSALANOVA et al. (1996), GRAHAM (1997), PACK e BEDFORD (1997) e ZANELLA et al. (1998), que demonstraram efeitos positivos no desempenho de frangos de corte, quando houve adição de enzimas em rações à base de milho e soja, formuladas com valores reduzidos de EM, PB e aminoácidos.

Não havendo diferenças entre os tratamentos, observa-se que a adição de complexo multienzimático e complexo multienzimático + lipase às rações pode ter melhorado a utilização da EM, da PB e dos aminoácidos (Met, Met+Cis e Lis) em 9; 7; e 5\%, respectivamente, em rações contendo milho e soja, estando de acordo com LYONS (1996).

\section{Experimento 2 - Digestibilidade}

As médias estimadas dos coeficientes de metabolização aparente da matéria seca (CMAMS), proteína bruta (CMAPB), energia bruta (CMAEB) e a energia metabolizável aparente corrigida para nitrogênio (EMAn) das rações experimentais à base de farelo de soja (FS) e soja integral extrusada (SIE) estão apresentadas na Tabela 5.

Não foram observadas diferenças entre os tratamentos para os CMAMS.

Para os tratamentos contendo FS e FS+SIE, verificou-se melhoria, embora não-significativa, de 8,2 e $2,1 \%$ do CMAPB, respectivamente, quando houve adição de CM. Este resultado sugere que, embora o aumento no CMAPB das rações não tenha sido significativo, a adição de enzimas às rações pode ter melhorado a digestibilidade da proteína da soja, o que, entretanto, não resultou em aumento no CMAPB da ração total.

McNab e Pugh (1993), citados por CHARLTON (1996), obtiveram aumento na digestibilidade verdadeira dos aminoácidos do farelo de soja, principalmente aqueles mais limitantes para aves quando houve suplementação enzimática. Resultados positivos também foram obtidos por GHASI et al. (1998a) em trabalhos com frangos utilizando alimentação forçada, que observaram aumento na retenção de nitrogênio com a adição de protease e alfagalactosidase ao farelo de soja.

MARSMAN et al. (1997) verificaram aumento na digestibilidade ileal da proteína bruta em frangos alimentados com dietas contendo soja extrusada, quando houve suplementação com enzimas. Estudando três

Tabela 5 - Coeficientes de metabolização aparente da MS (CMAMS), PB (CMAPB), EB (CMAEB) e EMAn das rações contendo farelo de soja (FS) e soja integral extrusada (SIE) suplementadas ou não com complexo multienzimático (CM)

Table 5 - Coefficients of apparent metabolization of dry matter (CAMDM), crude protein (CAMCP), gross energy (CAMGE) and AMEn of diets containing soybean meal (SM) and full fat extruded soybean (ES) supplemented or nor with multienzymatic complex (MC)

\begin{tabular}{|c|c|c|c|c|}
\hline $\begin{array}{l}\text { Tratamentos } \\
\text { Treatments }\end{array}$ & $\begin{array}{l}\text { CMAMS }(\%) \\
\text { CAMDM }(\%)\end{array}$ & $\begin{array}{l}\text { CMAPB }(\%)^{1} \\
C A M C P(\%)^{1}\end{array}$ & $\begin{array}{l}\text { CAMEB }(\%) \\
C A M G E(\%)\end{array}$ & $\begin{array}{c}\mathrm{EMAn}^{2} \\
A M E n^{2}\end{array}$ \\
\hline $\begin{array}{l}\text { A - FS sem CM } \\
A-S M \text { without } M C\end{array}$ & 67,91 & $51,28^{a}$ & 72,57 & 2850,99 \\
\hline $\begin{array}{l}\mathrm{B}-\mathrm{FS} \operatorname{com} \mathrm{CM} \\
B-S M \text { with } M C\end{array}$ & 68,43 & $55,87^{\mathrm{ab}}$ & 73,71 & 2873,55 \\
\hline $\begin{array}{l}\mathrm{C}-\mathrm{FS}+\mathrm{SIE} \text { sem CM } \\
C-S M+E S \text { without } M C\end{array}$ & 67,33 & $56,16^{\mathrm{ab}}$ & 72,45 & 2804,91 \\
\hline $\begin{array}{l}\mathrm{D}-\mathrm{FS}+\mathrm{SIE} \text { com CM } \\
D-S M+E S \text { with } M C\end{array}$ & 68,92 & $57,35^{\mathrm{b}}$ & 73,62 & 2848,50 \\
\hline $\mathrm{CV}(\%)$ & 2,41 & 4,75 & 1,70 & 1,81 \\
\hline
\end{tabular}

1 Médias na mesma coluna, seguidas de letras iguais, não diferem estatisticamente pelo teste de Tukey $(P>0,05)$.

2 Dados obtidos com base na matéria natural.

1 Means in the same column followed the same letters do not differ by Tukey Test $(P>0.05)$.

2 Obtained data on as fed basis. 
GARCIA et al.

tipos de soja processada, SAKOMURA et al. (1998) concluíram que a adição de enzimas às rações promoveu melhoria na digestibilidade da proteína bruta.

Para os CMAEB não foram observadas diferenças entre as rações contendo FS ou FS+SIE com ou sem adição de enzimas. Da mesma forma, os valores médios de EMAn das rações contendo FS não diferiram, quando houve suplementação enzimática, entretanto, verificou-se que a adição de enzimas promoveu aumento de $0,8 \%$ nos valores de EMAn dessas rações. Em trabalhos realizados com frangos, GHASI et al. (1998a) relataram que o tratamento enzimático promoveu incremento na EMVn do farelo de soja. De forma semelhante, GOMES et al. (1998) obtiveram aumento de 2,55\% da energia digestível de frangos colostomizados, quando estes receberam rações à base de milho e farelo de soja suplementadas com enzimas.

Para as rações contendo FS+SIE, embora não tenham sido observadas diferenças, também houve melhoria de 1,0\% nos valores de EMAn com adição de enzimas. McNab e Pugh (1993), citados por CHARLTON (1996), verificaram aumento de 5,2\% na EMVn do farelo de soja com a adição de enzimas, não tendo sido observado efeito sobre a soja integral. Por sua vez, SAKOMURA et al. (1998) e ZANELLA et al. (1998) obtiveram maiores valores de energia para as dietas contendo SIE, quando comparadas àquelas contendo FS ou soja integral tostada (SIT), contudo, a adição de enzimas apresentou efeito positivo sobre essas dietas.

Experimento 3 - Desempenho e fluxo de nutrientes na digesta ileal

Os resultados de desempenho das aves estão apresentados na Tabela 6.

Para o período inicial, não foram observadas diferenças no consumo de ração, no ganho de peso e na conversão alimentar entre as aves alimentadas com rações contendo FS como fonte protéica, com a adição ou não de complexo enzimático. Estes resultados diferem, em parte, daqueles obtidos por IRISH e BALNAVE (1993), CHARLTON, (1996), LESLIE (1996) e SEFTON e PERDOK (1996), que relataram aumento no ganho de peso de frangos, quando as rações contendo milho e soja foram suplementadas com enzimas. Já KONING et al. (1996) obtiveram melhoria no ganho de peso e na conversão alimentar das aves, quando houve suplementação enzimática.

Comparando os tratamentos contendo FS+SIE, verificou-se que adição de enzimas não promoveu diferenças entre as variáveis de desempenho. Resultados semelhantes foram observados por MARSMAN et al. (1997), visto que os autores não verificaram melhoria no desempenho das aves alimentadas com soja extrusada com a adição de proteases e carboidrases, no período de 7 aos 25 dias de idade.

No período de crescimento (22-42 dias) e no período total (1-42 dias), não foram verificadas diferenças entre os tratamentos em nenhuma das variáveis estudadas. Resultados contrários foram obtidos por GHASI et al. (1998b), que observaram aumento no ganho de peso e no consumo de ração à base de farelo de soja de aves em crescimento, embora não tenha ocorrido melhoria na conversão alimentar, quando houve adição de enzimas. Por outro lado, GRAHAM (1996) verificou melhoria na conversão alimentar de frangos com idade entre 8 e 42 dias, os quais foram alimentados com rações suplementadas com enzimas.

PERAZZO COSTA e BRANDÃO (1998) verificaram melhoria na conversão alimentar com a adição de diferentes níveis enzimáticos às dietas no período de crescimento (22-42 dias), entretanto, na fase final (43-49 dias), estes níveis não apresentaram efeito. Da mesma forma, FIGUEIREDO et al. (1998), comparando rações à base de milho e três tipos de soja processada, observaram melhoria no ganho de peso e na conversão alimentar das aves, no período de 1 a 45 dias de idade.

Os resultados referentes às análises de fluxo de matéria seca (FMS), alfa-glicosídeos solúveis em etanol (AGSE) e alfa-glicosídeos insolúveis em etanol (AGIE) estão apresentados na Tabela 7.

Não foram observadas diferenças entre os tratamentos quanto aos valores de FMS na digesta ileal, aos 21 e 42 dias de idade.

Aos 21 dias de idade, para os tratamentos contendo FS e FS+SIE, observou-se aumento, embora nãosignificativo, na concentração dos AGSE, quando houve adição de enzimas. Os AGSE incluem a fração de carboidratos com menos de 20 unidades de glicose na cadeia, incluindo, portanto, os oligossacarídeos. Este resultado sugere que, provavelmente, as enzimas hidrolisaram os polissacarídeos presentes nas rações produzindo oligossacarídeos, conforme sugerido por IRISH e BALNAVE (1993), que observaram aumento na concentração de oligossacarídeos no conteúdo intestinal de aves que receberam dietas contendo farelo de soja, suplementadas com diferentes preparados enzimáticos.

Aos 42 dias de idade, a concentração de AGSE não diferiu entre os tratamentos.

Os valores de AGIE que incluem a fração de carboidratos com mais de 20 unidades de glicose na 
1424 Rev. bras. zootec.

Tabela 6 - Desempenho de frangos de corte alimentados com rações contendo farelo de soja (FS) e soja integral extrusada (SIE), suplementadas ou não com complexo multienzimático (CM)

Table 6 - Performance of broilers fed with diets containing soybean meal (SM) and full fat extruded soybean (ES) supplement with or not with multienzymatic complex (MC)

\begin{tabular}{|c|c|c|c|}
\hline $\mathrm{CV}(\%)$ & 2,58 & 3,51 & 2,29 \\
\hline & \multicolumn{3}{|c|}{$22-42$ dias } \\
\hline $\begin{array}{l}\text { A - FS sem CM } \\
A-S M \text { without } M C\end{array}$ & 3060,11 & 1482,16 & 2,065 \\
\hline $\begin{array}{l}\mathrm{B}-\mathrm{FS} \text { com CM } \\
B-S M \text { with } M C\end{array}$ & 3219,08 & 1583,73 & 2,034 \\
\hline $\begin{array}{l}\text { C- FS+SIE sem CM } \\
C-S M+E S \text { without } M C\end{array}$ & 3073,53 & 1501,11 & 2,05 \\
\hline $\begin{array}{l}\mathrm{D}-\mathrm{FS}+\mathrm{SIE} \text { com CM } \\
D-S M+E S \text { with } M C\end{array}$ & 3147,43 & 1530,23 & 2,058 \\
\hline \multirow[t]{2}{*}{$\mathrm{CV}(\%)$} & 3,70 & 5,17 & 2,52 \\
\hline & \multicolumn{3}{|c|}{$1-42$ dias } \\
\hline $\begin{array}{l}\text { A - FS sem CM } \\
A-S M \text { without } M C\end{array}$ & 4090,13 & 2173,23 & 1,883 \\
\hline $\begin{array}{l}\text { B - FS com CM } \\
B-S M \text { with } M C\end{array}$ & 4302,37 & 2302,92 & 1,869 \\
\hline $\begin{array}{l}\mathrm{C}-\mathrm{FS}+\mathrm{SIE} \text { sem } \mathrm{CM} \\
C-S M+E S \text { without } M C\end{array}$ & 4095,88 & 2174,60 & 1,885 \\
\hline $\begin{array}{l}\text { D- FS+SIE com CM } \\
D-S M+E S \text { with } M C \\
\end{array}$ & 4188,95 & 2215,98 & 1,892 \\
\hline $\mathrm{CV}(\%)$ & 3,24 & 4,49 & 2,20 \\
\hline
\end{tabular}

${ }^{1}$ Médias, na coluna, seguidas de letras iguais, não diferem pelo teste Tukey $(P>0,05)$.

${ }^{1}$ Means, within a column, followed by the same letters do not differ by Tukey Test $(P>.05)$.

cadeia não diferiram aos 21 dias de idade. Entretanto, aos 42 dias de idade, observou-se redução, embora não-significativa, na concentração de AGIE na digesta ileal para os tratamentos contendo FS, com a adição de enzimas, demonstrando que provavelmente os polissacarídeos presentes nas rações foram hidrolisados, em função da ação enzimática. Por outro lado, para os trata- mentos contendo FS+SIE, não foram observadas diferenças para os valores de AGIE, quando foram adicionadas enzimas.

LONKHUIJSEN et al. (1997) relataram que a hidrólise dos carboidratos da parede celular promovida por enzimas exógenas produz, além de glicose, mono, di, tri e oligossacarídeos, que, no intestino, podem reduzir a digestibilidade dos alimentos. 
GARCIA et al.

Tabela 7 - Fluxo de matéria seca (FMS), alfa-glicosídeos solúveis em etanol (AGSE) e alfa-glicosídeos insolúveis em etanol (AGIE), determinados na digesta ileal, de frangos de corte aos 21 e 42 dias

Table 7 - Dry matter flow (DMF), alpha-glucoside soluble in ethanol (AGSE) and alpha-glucoside insoluble in ethanol (AGIE) determined in the ileal digesta of broilers at 21 and 42 days

\begin{tabular}{|c|c|c|c|}
\hline $\begin{array}{l}\text { Tratamentos } \\
\text { Treatments }\end{array}$ & $\begin{array}{l}\mathrm{FMS}(\mathrm{g}) \\
D M F(g)\end{array}$ & $\begin{array}{l}\operatorname{AGSE}(\mathrm{mmol})^{2} \\
A G S E(\mathrm{mmol})^{2}\end{array}$ & $\begin{array}{l}\mathrm{AGIE}(\mathrm{mmol})^{2} \\
A G I E(\mathrm{mmol})^{2}\end{array}$ \\
\hline & \multicolumn{3}{|c|}{21 dias } \\
\hline $\begin{array}{l}\text { A - FS sem CM } \\
A-S M \text { without } M C\end{array}$ & 23,95 & 2,92 & 68,11 \\
\hline $\begin{array}{l}\mathrm{B}-\mathrm{FS} \operatorname{com} \mathrm{CM} \\
B-S M \text { with } M C\end{array}$ & 23,93 & 4,46 & 74,24 \\
\hline $\begin{array}{l}\mathrm{C}-\mathrm{FS}+\mathrm{SIE} \text { sem CM } \\
C-S M+E S \text { without } M C\end{array}$ & 25,26 & 3,88 & 78,46 \\
\hline $\begin{array}{l}\mathrm{D}-\mathrm{FS}+\mathrm{SIE} \text { com CM } \\
D-S M+E S \text { with } M C\end{array}$ & 26,52 & 5,79 & 78,17 \\
\hline \multirow[t]{2}{*}{$\mathrm{CV}(\%)$} & 16,43 & 47,72 & 49,58 \\
\hline & \multicolumn{3}{|c|}{42 dias } \\
\hline $\begin{array}{l}\text { A - FS sem CM } \\
A-S M \text { without } M C\end{array}$ & 33,03 & 1,80 & 106,58 \\
\hline $\begin{array}{l}\mathrm{B}-\mathrm{FS} \text { com CM } \\
B-S M \text { with } M C\end{array}$ & 31,77 & 1,87 & 77,43 \\
\hline $\begin{array}{l}\mathrm{C}-\mathrm{FS}+\mathrm{SIE} \text { sem CM } \\
C-S M+E S \text { without } M C\end{array}$ & 28,30 & 2,20 & 87,45 \\
\hline $\begin{array}{l}\mathrm{D}-\mathrm{FS}+\mathrm{SIE} \text { com CM } \\
D-S M+E S \text { with } M C\end{array}$ & 28,56 & 2,64 & 83,33 \\
\hline $\mathrm{CV}(\%)$ & 11,19 & 62,89 & 34,31 \\
\hline
\end{tabular}

\section{Conclusões}

A adição de complexo multienzimático em rações com farelo de soja e soja integral extrusada para frangos de corte (1-42 dias) foi efetiva na melhoria da utilização de energia metabolizável, proteína e aminoácidos (Met, Met+Cis e Lis) em 9; 7; e 5\%, respectivamente.

Devem ser conduzidos mais estudos utilizando a enzima lipase, nas dietas iniciais de frangos de corte, a qual, nesta fase, pode trazer grandes benefícios quanto ao desempenho da ave.

Os coeficientes de metabolização da matéria seca, proteína bruta e energia bruta e a EMAn das rações experimentais não foram influenciados pela adição de enzimas.

A adição de enzimas as rações à base de milho e soja não promoveu melhoria no desempenho de frangos de corte (1-42 dias).

Não houve influência da suplementação de enzimas sobre o fluxo de nutrientes na digesta ileal de frangos de corte aos 21 e 42 dias de idade.

\section{Referências Bibliográficas}

CAFÉ, M.B. Estudo do valor nutricional da soja integral processada para aves. Jaboticabal: UNESP, 1993. 97p. Dissertação (Mestrado em Zootecnia) - Faculdade de Ciências Agrárias e Veterinárias, UNESP, 1993.

CHARLTON, P. Expanding enzyme application: higher aminoacid and energy values for vegetable proteins. In: BIOTECHNOLOGY IN THE FEED INDUSTRY, 12, 1996, Nottingham. Proceedings...Nottingham: Nottingham University Press, 1996. p.317-326.

CLEÓPHAS, G.M.L., Van HARTINGSVELDT, W., SOMERS, W.A.C. et al. 1995. Enzymes can play an important role in poultry nutrition. World Poult., 11(4):12-15.

FIGUEIREDO, A.N., ZANELLA, I., SAKOMURA, N.K. et al. Efeito da adição de enzimas em dietas à base de milho e tipos de soja sobre o desempenho de frangos de corte. In: CONFERÊNCIA APINCO DE CIÊNCIA E TECNOLOGIA AVÍCOLAS, 1998, Campinas. Anais...Campinas: FACTA, 1998. p.36.

GHASI, S., ROOKE, H., GALBRAITH, H. et al. 1998a. Effect of adding protease and alpha-galactosidase enzymes to soybean meal on nitrogen retention and true metabolizable energy in broilers. Br. Poult. Sci., 38(supl.):S28.

GHASI, S., ROOKE, H., GALBRAITH, H. et al. 1998b. Effect of feeding growing chicks semi-purified diets containing 
1426 Rev. bras. zootec.

soyabean meal and different amounts of protease and alphagalactosidase enzymes. Br. Poult. Sci, 38(supl.):S29.

GOMES, L.F., MACARI, M., FURLAN, R.L. et al. Efeito do uso de enzimas sobre a digestibilidade de dieta à base de milho e farelo de soja em frangos de corte colostomizados. In: CONFERÊNCIA APINCO DE CIÊNCIA E TECNOLOGIA AVÍCOLAS, 1998. Campinas. Anais...Campinas: FACTA, 1998, p.6.

GRAHAM, H. 1996. Enzymes broaden scope of dietary ingredients. World Poult., 12(7):24-25.

GRAHAM, H. 1997. Enzimas para dietas de maíz-soya para parrilleros. Alimentos Balanceados para Animales, 4(6):22-24.

IRISH, G.G., BALNAVE, D. 1993. Non-starch polysaccharides and broiler performance on diets containing soybean meal as the sole protein concentrate. Aust. J. Agric. Res., 44(7):1483-1499.

KONING, W.J., WALKER, A.W., SCHUTTE, J.B. 1996. Effect of Allzyme PF (Allzyme Vegpro) on non starch polysaccharide digestibility in broilers fed vegetable proteins. In: ALLTECH. The potential of soybeans has just been unleashed. 30p.

KREIKEMEIER, K.K., HARMON, D.L. 1995. Abomasal glucose, maize starch and maize dextrin infusions, in cattle: small-intestinal disappearance, net portal glucose flux and ileal oligosaccharide flow. Br. J. Nut., 73(5):763-772.

KROGDAHL, A., SELL, J. 1989. Influence of age on lipase, amylase and protease activities in pancreatic tissue and intestinal contents of young turkeys. Poult. Sci., 68(11):1561-1568.

LESLIE, A.J. The ever increasing role of the biotechnology in the Poultry Industry: Lessons from the past and thoughts for the future. In: NORTH AMERICAN UNIVERSITY TOUR, 1996, Nicholasville. Proceedings... Nicholasville: Alltech, 1996. p.65-85.

LONKHUIJSEN, H., GELDER, A., JETTEN, J. et al. 1997. 3-step NSP analysis. Feed Mix, 5(5):14-16

LYONS, T.P. Goal 2000: A truly global science - based company that responds rapidly to emerging issues. In: NORTH AMERICAN UNIVERSITY TOUR. 1996, Nicholasville, Proceedings... Nicholasville: Alltech, 1996. p.1-32.

MARSMAN, G.J.P., GRUPPEN, H., VANDER POEL, A.F.B. et al. 1995. The effect of shears forces and addition of a mixture of a protease and a hemicellulase on chemical, physical and physiological parameters during extrusion of soybean meal. Anim. Feed Sci. Technol., 56(1-2):21-35.

MARSMAN, G.J.P., GRUPPEN, H., VANDER POEL, A.F.B. et al. 1997. The effect of thermal processing and enzyme treatments of soybean meal on growth performance, ileal nutrient digestibilities, and chyme characteristics in broiler chicks. Poult. Sci., 76(6):864-872.

PACK,M., BEDFORD, M. 1997. Feed enzymes for cornsoybean broiler diets. Word Poult., 13(9):87-93.

PERAZZO COSTA, F.G., BRANDÃO, J.S. Efeito de cinco níveis de enzimas na fase de crescimento e final, sobre o desempenho de frangos de corte. In: CONFERÊNCIA APINCO DE CIÊNCIA E TECNOLOGIA AVÍCOLAS, 1998, Campinas. Anais... Campinas: FACTA. 1998. p.17.

PEREIRA, J.R.A., ROSSI, P. 1995. Manual prático de avaliação nutricional de alimentos. Piracicaba: FEALQ. 25p.
POORE, M.H., ECK, T.P., SWINGLER, R.S. et al. Total starch and relative starch availability of grains. In: BIENAL CONFERENCE ON RUMEN FUNCTION, Chicago, 1989, Abstracts... Chicago, 1989, v.20, p.35.

PUGH, R. The scope for enzymes in commercial feed formulations. In: BIOTECHNOLOGY IN FEED INDUSTRY, 9, 1993, Nottingham. Proceedings...Nottingham: Nottingham University Press, 1993. p.369-372.

ROSTAGNO, H.S., SILVA, D.J., COSTA, P.M.A. et al. 1987. Composição de alimentos e exigências nutricionais de aves e suínos (Tabelas brasileiras). Viçosa, UFV: Impr. Univ. p.59.

SAKOMURA, N.K., ZANELLA, I., LONGO, F.A. et al. Efeito da suplementação de um complexo enzimático em dietas à base de milho e soja sobre a digestibilidade em aves. In: CONFERÊNCIA APINCO DE CIÊNCIA E TECNOLOGIA AVÍCOLAS, 1998, Campinas. Anais... Campinas: FACTA, 1998. p.38.

SCHANG, M.J. O uso da enzima Vegpro em dietas para frangos em crescimento. In: RONDA LATINOAMERICANA DE BIOTECNOLOGIA, 6, 1996, Caribe. Proceedings...Caribe: Alltech, 1996, p.71-77.

SEFTON, A.E., PERDOK, H. 1996. Effect of inclusion of Allzyme Vegpro in a broiler starter diet. In: ALLTECH. The potential of soybeans has just been unleashed. 30p.

SILVA, D.J. 1990. Análise de alimentos (Métodos químicos e biológicos). Viçosa, UFV: Imprensa Universitária. 165p.

SOTO-SALANOVA, M.F., GARCIA, O., GRAHAM, H. et al. Uso de enzimas em dietas de milho e soja para frangos de corte. In: CONFERÊNCIA APINCO DE CIÊNCIA E TECNOLOGIA AVÍCOLAS, 1996, Curitiba. Anais...Curitiba:FACTA, 1996. p.71-76.

WARD, N.E., FODGE, D. 1996. Ingredients to counter antinutritional factors: soybean - based feeds need enzymes too. Feed Management, 47(10):13-18.

WIGGINS, H.S. 1984. Nutritional value of sugars and related compounds undigested in the small gut. Proc. Nut. Society, 43:69-75.

WILLIANS, C.H., DAVID, D.J., IISMA, O. 1962. The determination of cromic oxide in faeces samples by atomic absorption spectrophotometry. J. Agric. Sci., 59(3):381.

ZANELLA, I., SAKOMURA, N.K., PACK, M. et al. Efeito da adição de enzimas sobre a digestibilidade ileal e desempenho em frangos de corte alimentados com dietas à base de milho e soja. In: CONFERÊNCIA APINCO DE CIÊNCIA E TECNOLOGIA AVÍCOLAS, 1998, Campinas. Anais... Campinas: FACTA, 1998. p.37.

Recebido em: 03/02/99

Aceito em: 09/03/00 